\title{
Tempos da infância: entre um poeta, um filósofo, um educador
}

\author{
Walter Omar Kohan ${ }^{1}$ \\ ORCID: 0000-0002-2263-9732 \\ Rosana Aparecida Fernandes ${ }^{2}$ \\ ORCID: 0000-0002-6166-1780
}

\section{Resumo}

A ideia central que aqui apresentaremos é que há um valor político na temporalidade infantil, que é preciso atentar e cuidar, muito mais do que interromper, como fazem, atualmente, as instituições educacionais. Assim, os modos de entender o político exigem repensar a experiência temporal propiciada e afirmada nas instituições educacionais. Nossa estratégia é chamar personagens infantis, vindos da literatura, da filosofia e da educação: Gonzalo Rojas, Gilles Deleuze e Paulo Freire. Um conceito atravessa o presente ensaio: o tempo. Na poesia de Gonzalo Rojas, o esforço do poeta é por honrar o tempo presente da infância que é, também, o tempo da escrita poética. Eis o tempo da reniñez: um tempo que não passa, durativo, atento e sensível à palavra do mundo. Com Gilles Deleuze, pensar a infância como uma cena infantil é restaurar à infância um tempo propriamente infantil, como diz Heráclito no seu icônico fragmento 52. Finalmente, Paulo Freire expande o tempo da infância para todas as idades: invasão aiónica de khrónos, que torna urgente aos educadores e às educadoras de todas as idades, ao habitar um tempo infantil, um presente curioso que olha o mundo com estranheza e pergunta, inquieto, por que o mundo é como é e de que outras maneiras ele poderia ser. Com Freire, ouvíamos uma palavra infantil para pensar o sentido da presença da filosofia na escola: ele não diz respeito a fazer da infância algo diferente do que ela é, mas nos lembra e nos leva à (um tempo de) infância.

\section{Palavras-chave}

Infância - Gonzalo Rojas - Gilles Deleuze - Paulo Freire.

1- Universidade do Estado do Rio de Janeiro (UERJ), Rio de Janeiro, RJ, Brasil. Contato: wokohan@gmail.com

2- Universidade Federal de Rio Grande do Sul (UFRGS), Porto Alegre, RS, Brasil. Contato: rosanafernandes.edu@gmail.com

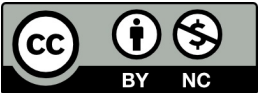




\section{Times of childhood: among a poet, a philosopher and an educator}

\section{Abstract}

The main idea of this text is that there is a political value in children's temporality, which needs to be looked after and cared for much more than interrupted, as educational institutions do today. Thus, the ways of understanding the political context require reconsidering the temporal experience which is being provided and affirmed in educational institutions. Our strategy is to focus on three childlike characters, who come from literature, philosophy and education: Gonzalo Rojas, Gilles Deleuze and Paulo Freire. Time is a concept that permeates this essay. In the poetry of Gonzalo Rojas, the poet strives to honor the present time of childhood which is also the time of poetic writing. This is the time of reniñez: a time that does not pass, which is long-lasting, attentive and sensitive to the word of the world. For Gilles Deleuze, conceptualizing childhood as a "childlike scene" means to restore to childhood a truly infantile time, as Heraclitus says in his iconic 'Fragment 52'. Finally, Paulo Freire expands childhood's time to all ages: the aionic invasion of khronos, which urges educators of all ages to inhabit childhood's time, a curious gift that makes one look surprised at the world with and restlessly wonder why the world is as it is and how different it could be. With Freire, we listen to a child's word to think about the meaning of the presence of philosophy in school: it is not about making childhood something different from what it is, but it reminds us and leads us to childhood times.

\section{Keywords}

Childhood - Gonzalo Rojas - Gilles Deleuze - Paulo Freire.

Consegui com uma mão filmar a outra, e apanhar os caminhões durante as longas horas de viagem. Agnès Varda

\section{Primeiras palavras}

Recebemos o convite para escrever um texto para uma seção temática comemorando os 30 anos do Estatuto da Criança e Adolescente (ECA). 0 convite propunha uma relação mais alargada com o ECA, justamente com aquilo que ele propõe nos termos das garantias e conquistas acerca da criança como sujeito de direitos. 0 convite dá destaque a um intuito por pensar as múltiplas facetas do espaço-tempo da infância como elemento constitutivo da própria ideia de democracia, ou seja, para pensar as relações entre infância e política. 
Eis que passadas algumas hesitações e dúvidas a respeito do significado institucional e político do ECA, resolvemos aceitar o convite fazendo uma leitura efetivamente alargada para pensar em particular a relação entre infância e tempo, a partir de uma interlocução com figuras inscritas nos mundos da literatura, da filosofia e da educação. Não nos referimos explicitamente ao ECA, mas, confiamos que algumas ideias aqui apresentadas podem contribuir para pensar seu significado institucional e político.

Vale também esclarecer que, por se tratar de um ensaio, não há qualquer pretensão de estabelecer ou fixar categorias ou linhas de leitura abrangentes ou omnicompreensivas. Afirmamos, ao contrário, certa abdicação do princípio da identidade. Portanto, os autores com os quais aqui trabalhamos, Rojas, Deleuze e Freire, têm o valor de intercessores na construção de uma escrita aberta e experimental, que movimenta os modos de pensarmos as questões aqui abordadas.

0 resultado, esperamos, será desafiador para pensar a própria ideia de democracia ou do político, para dizê-lo em termos mais amplos. A ideia central que aqui apresentaremos é que há um valor político na temporalidade infantil, que é preciso atentar e cuidar, muito mais do que interromper, como fazem, atualmente, as instituições educacionais. Assim, os modos de entender o político exigem repensar a experiência temporal propiciada e afirmada nas instituições educacionais. Talvez, seja oportuno lembrar que a própria palavra escola deriva de uma palavra grega com significado temporal (skholé, "tempo livre") e que as escolas surgiram, na Antiga Grécia, não como espaços para aprender (pois não é preciso uma escola para aprender; pode se aprender em casa, na fábrica etc.), mas para separar e suspender o tempo social, propiciando aos escolares uma experiência de tempo liberada das exigências e valores socialmente dominantes (MASSCHELEIN; SIMONS, 2014).

De certo modo, seguimos esse caminho. Nossa estratégia é chamar personagens infantis, vindos da literatura, da filosofia e da educação. Demos nome aos bois: Gonzalo Rojas, Gilles Deleuze 3 , Paulo Freire. Logo alguém poderia pensar nos contrastes das fıguras aqui escolhidas; seus campos conceituais e estilos diversos, referenciais teóricos encontrados. Por exemplo, poderia chamar a atenção um eventual embate entre alguém que tem dado destaque à própria infância biográfica como Paulo Freire, e a explícita crítica de Gilles Deleuze aos que vasculham nos arquivos familiares para remeter à própria biografia. Ou, então, poderia se questionar a associação que fazemos entre um vanguardista surrealista com as pretensões políticas emancipadoras do pensamento pedagógico de Paulo Freire. Não desconhecemos essas latentes tensões e pedimos certa paciência do leitor para ver o resultado deste ensaio de conjunções e conexões. Colocamo-nos entre os três, porque uns e outros, desde os seus lugares de criação e de problematização, perguntam e nos ajudam a perguntar e tornar a pensar o que cremos saber acerca da infância, em sua relação com o tempo e a política.

3- Propomos Gilles Deleuze, e não a dupla Deleuze-Guattari, porque os principais textos nos quais nos baseamos em $A$ cena infantil de um filósofo são todos de autoria de Gilles Deleuze e não coautorias. De qualquer forma, num sentido mais profundo, a distinção é quase irrelevante pela postura anti-identitária do mencionado autor e do presente texto. 


\title{
Um poeta criança
}

Na língua castelhana há duas palavras para dizer infância: niñez e infancia. Na língua coloquial elas são intercambiáveis, têm o mesmo significado. Diferentemente, para dizer criança existe niño ou niña e muitas outras palavras diferentes a depender de cada país. ${ }^{4}$ Gonzalo Rojas, poeta chileno (1916-2011), publicou um livro com o sugestivo título de uma palavra por ele mesmo inventada: Reniñez. ${ }^{5} 0$ livro contém poemas de diversas épocas e, dentre eles, um de 1999 que dá o título ao livro.

Gonzalo Rojas nasceu em Lebu, sul do Chile, em 1916. Sua infância, na pobreza, não foi feliz. ${ }^{6}$ Perdeu cedo o seu pai e o golpe de graça foi quando roubaram o cavalo que o pai lhe tinha deixado de presente. Teve asma. Aprendeu tarde, mas muito rápido a ler (com 9 anos, em 3 meses), e gaguejava na leitura imposta mecanicamente na escola. Mas lia sem parar, apaixonadamente, em segredo. Desde pequeno, sua vida esteve atravessada por viagens, primeiro dentro do Chile: com 8 anos viajou a Concepción com sua mãe viúva e seus sete irmãos; depois, entediado de Concepción, viajou a Iquique sozinho, de barco, para terminar ali a escola média. Mais tarde, viajou a Santiago para estudar Direito. Depois, já dedicava-se inteiramente às letras, e, de novo, foi ao norte, em direção a Atacama. Ali reencontrou a pobreza e, em El Orito, a 3.000 metros de altitude, alfabetizou 200 mineiros com fragmentos de Heráclito.

\begin{abstract}
Ainda me lembro das deslumbrantes cordilheiras de El Orito, que ainda andam comigo pelo mundo, e daqueles 200 mineiros analfabetos que me ensinaram quase tanto quanto as estrelas. Analfabetos, mas com um maravilhoso imaginário e um pensamento mágico que não vi nunca nos poetas mais pintados. Que Mandrágora ou que surrealismo. Certa vez, pensei que era bom ensiná-los também - depois do trabalho - à noite, à luz de lâmpadas de carbureto, depois de turnos suados. Alguns estavam interessados e, como eu não tinha material didático, a não ser de alguns livros amados que consegui colocar na minha mala na despedida de Santiago, aproveitei alguns textos dos filósofos pré-socráticos para jogar o jogo de vogais e sílabas. Eu li alguns fragmentos e eles preferiram os de Heráclito. Foi assim que, no auge da juventude, e em meu longo aprendizado como poeta, que não termina ainda depois de tantas décadas, eu passei a realizar tarefas de alfabetização entre as altas neves do Chile, ensinando a ler no silabário de Heráclito. (ROJAS, 2004, p. 363, tradução nossa).?
\end{abstract}

\footnotetext{
4- Na Argentina, por exemplo, depende da região, niño e niña é usado muito em algumas regiões, mas na capital quase não se usa, mas, sim, chico ou chica. No Chile, preferem-se expressões de animais, como, por exemplo, cabro ou cabro chico. No Uruguai, é muito popular botija, e assim por diante... Nesses países, hoje, há um movimento muito forte de gênero para desmasculinizar a linguagem e usar, por exemplo, a letra "e" como marca de gênero: niñes.

5- A primeira edição do livro foi publicada em 2004, pela editora Tabla Rasa.

6- Para os dados biográficos, confira (CNCA; GONZÁLEZ FULLE; CLARO EYZAGUIRRE, 2017).

7- "Aún recuerdo las cordilleras deslumbrantes de El Orito que todavía andan conmigo por el mundo y a esos 200 mineros analfabetos que me enseñaron casi tanto como las estrellas. Analfabetos pero con un portento imaginario y un pensamiento mágico que no vi nunca en los poetas más pintados. Qué Mandrágora ni qué surrealismo. Cierta vez pensé que también era bueno enseñarles a ellos — después de su trabajo — de noche, a la luz de las lámparas de carburo, después de los turnos sudorosos. Algunos se interesaron y como yo no disponía de material didáctico sino de unos pocos libros amados que alcancé a meter en mi maleta en el adiós a Santiago, aproveché unos textos de los filósofos presocráticos para jugar el juego de las vocales y las sílabas. Les leí algunos fragmentos y ellos prefirieron los de Heráclito. Así fue cómo, en plena edad juvenil, y en mi largo aprendizaje de poeta que no termina aún después de tantas décadas, vine a cumplir faenas de apir alfabetizador entre las altas nieves de Chile enseñando a leer en el silabario de Heráclito" (ROJAS, 2004, p. 363).
} 
A seguir, viveu em Valparaíso e, novamente, em Concepción. Com o governo socialista de Salvador Allende passou a ser agregado cultural na China e em Cuba. Com a ditadura, em 1973, iniciou um exílio pela então chamada Alemanha Oriental, Venezuela e Estados Unidos. Passou por Chile, onde foi proibido de lecionar, e continuou viajando pelo mundo, lecionando em universidades da Alemanha Federal, Estados Unidos, Suécia e México.

Eu me deixei levar pelo vento, e o vento sabe. Quem não é um rulfiano em nossa América? Sou filho de um mineiro, um mineiro abastado, mas um mineiro. Meu pai cortou veias de carvão no início do século no Golfo de Arauco. Morreu cedo o homem, a um milímetro do gás grisu, como todos os mineiros. Por isso, subi a colina, como Rulfo disse: em busca do meu pai. Não é que eu seja um poeta genealógico, mas acredito na genealogia dos labirintos; na genealogia da geologia, e eu amo as pedras. (ROJAS, 2004, p. 363-364, tradução nossa). ${ }^{8}$

A poesia de Gonzalo Rojas é infantil: sem ordem, caótica, apaixonada, livre, amorosa. Rojas inventa ou resgata muitas palavras em desuso, em geral, incorporando prefixos, por exemplo: transtierro ${ }^{9}$. Na língua castelhana é habitual destierro, que supõe um "ter que deixar a própria terra"; o transtierro parece menos violento, como se parte da própria terra se deslocasse, junto, na viagem. ${ }^{10}$ Outra palavra criada é Reniñez, do prefixo re + o substantivo niñez. ${ }^{11} 0$ sentido dessa palavra é apresentado pelo próprio Rojas, já muito longe da infância cronológica, na velhice. É ali que se vive a reniñez, uma espécie de repetição livre e complexa da infância, a verdadeira pátria do poeta. Consideremos o próprio poema la reniñez:

Dizem que o século se vai, que o milênio se vai, qual milênio?, qual século? Da era de quê? Talvez fosse o caso de se calar. Mas não. Ainda não. Pelo menos, ainda não. Estou vivendo um reverdejar no melhor sentido, uma reinfância, uma espontaneidade que quase não consigo explicar. É como se eu deixasse que a língua escrevesse por mim. Parece descuido, mas não poderia haver desvelo maior. Estou deixando que as águas falem, que subam as águas e que elas mesmas falem. (ROJAS, 2015, tradução nossa). ${ }^{12}$

A reniñez vive-se em um tempo que questiona os tempos mensurados, medidos, metrados. É o passado que se renova e se faz presente, um novo presente que vem do

\footnotetext{
8- "Me dejé llevar por el viento, y el viento sabe. ¿Quién que es no es rulfiano em nuestra América? Soy hijo de minero, de minero más bien acomodado, pero minero al fin. Mi padre cortó vetas de carbón al empezar el siglo frente al Golfo de Arauco. Murió temprano el hombre, a un milímetro siempre del gas grisú como todos los mineros. A eso fui cerro arriba, como dijera Rulfo: en busca de mi padre. No es que sea un poeta genealógico pero creo en la genealogía de los laberintos; en la genealogía de la geología, y amo las piedras" (ROJAS, 2004, p. 363-364).

9- É o título de um dos livros G. Rojas: Transtierro. Madrid: Taranto, 1979.

10- Rojas $(2015$, p. 126) afirma que o destierro significa a perda da terra e da própria língua, pois o exílio é em um país que fala outra língua, enquanto no transtierro a língua materna se mantém. № caso de Rojas, a Alemanha Oriental seria um caso de destierro e a Venezuela de transtierro. 11- Rojas inventa a palavra em 1988 , como vimos, também é um título de um livro de poemas de Rojas.

12- "Dicen que el siglo se va, que el milenio se va, ¿cuál milenio?, ¿cuál siglo? ¿De la era de qué? A lo mejor debiera uno callarse. Pero no. Todavía no. Por lo menos todavía no. Estoy viviendo un reverdecimiento en el mejor sentido, una reniñez, una espontaneidad que casi no me explico. Es como si yo dejara que escribiera el lenguaje por mí. Parece descuido, y es el desvelo mayor. Estoy dejando que las aguas hablen, que suban las aguas, y que ellas mismas hablen." (ROJAS, 2015).
} 
passado, no qual a duração da espontaneidade e a atenção ao mundo fazem com que ele não passe. Quase inexplicável, é um reverdecer, um reviver, um ganhar nova força e vitalidade. É uma subjetividade em silêncio, quase calada: quase porque ainda tem palavra, só que é a palavra que fala pelo sujeito e não o sujeito que fala sua palavra. É a palavra que vem de fora, do mundo e não do interior de si. É o desvelo maior, supremo: o cuidado por silenciar a própria palavra para escutar a palavra do mundo. Assim, a reniñez é uma imaginação aberta e atenta. Supõe risco e coragem, abertura ao mundo, à infância, à infância do mundo.

\section{A cena infantil de um filósofo}

Gilles Deleuze foi um filósofo sedentário, de saúde frágil, para quem sempre foi difícil deitar-se tarde. Saiu poucas vezes de Paris e foi bastante hostil às viagens, ou pelo menos ao que considerava as condições em que um intelectual viaja. Pensava que as rupturas são mais importantes do que as viagens e ponderava que as rupturas poderiam acontecer sem sair fisicamente do lugar - como na própria biblioteca -, assim como é possivel deslocar-se longamente em sentido espacial, sem que nenhuma ruptura de fato aconteça (cf. L' ABÉCÉDAIRE de Gilles Deleuze, 2001, letra “v” como viagem). Também era fascinado pelos nômades que, afirmava, aí mesmo, não saem do lugar.

Deleuze viaja no pensamento e seu pensamento (escrito, filmado, traduzido), propicia viagens no pensamento, sem sair de casa. Trata-se de algo muito propício em tempos de confinamento pelo COVID-19. Ante uma pergunta de Claire Parnet, sobre se a sua aversão por viagens está ligada à sua lentidão natural, Deleuze responde:

\footnotetext{
Não, porque pode haver viagens lentas. Não preciso sair. Todas as intensidades que tenho são imóveis. As intensidades se distribuem no espaço ou em outros sistemas que não precisam ser espaços externos. Garanto que, quando leio um livro que acho bonito, ou quando ouço uma música que acho bonita, tenho a sensação de passar por emoções que nenhuma viagem me permitiu conhecer. Por que iria buscar estas emoções em um sistema que não me convém quando posso obtê-las em um sistema imóvel, como a música ou a filosofia? Há uma geo-música, uma geo-filosofia. São países profundos. São os meus países. (L' ABÉCÉDAIRE de Gilles Deleuze, 2001, letra “v” como viagem).
}

Deleuze interessa-se pelos trajetos que as crianças traçam, o modo como abrem e encerram conexões com facilidade, suas atividades cartográficas, seus percursos e devires. "A criança não para de dizer o que faz ou tenta fazer: explorar os meios, por trajetos dinâmicos, e traçar o mapa correspondente" (DELEUZE, 1997, p. 73). Contudo, a infância que mais interessa a Deleuze não é a infância cronológica, mas a infância como potência de movimento e de transformação, em sua particular relação com a força política e criativa do molecular: uma linha de fuga perante o sistema e os universalismos de diversas espécies.

Uma dessas formulações acerca da infância aparece no capítulo 2, de Diferença e Repetição (1988a), “A repetição para si mesma”, um capítulo que trata da memória, do tempo bergsoniano, do passado puro que Bergson (1999) expõe em Matéria e Memória e 
A Evolução Criadora (1964), bem como da repetição e do eterno retorno nietzschiano. É nesse capítulo que Deleuze apresenta a ideia de "cena infantil" (DELEUZE, 1988a, p. 206), uma ideia que nos interessa explorar aqui pelos seus efeitos para pensar a infância e sua relação com o tempo.

A cena infantil é, para Deleuze, cristal do tempo, é pura indiscernibilidade, é coalescência, é circuito estreito de um atual e de um virtual que se intercambiam o tempo todo, coexistem, e contêm, sempre, uma parte que não se efetua, que sobrepõe os corpos como um vapor incorporal. É o tempo aion que confunde khrónos, subdividindo o presente da cena infantil em acontecimento já passado e ainda por vir, e a faz contemporânea da adultez. Aion, alterando a lógica de sucessão consecutiva na forma de passado-futuro de khrónos, é o agente da reniñez, um passado que se faz presente. É Mnemósina que dá à cena infantil um passado puro, "um passado que jamais foi presente.” (DELEUZE, 1988a, p. 145, itálico do autor), porque ele não passa como o presente, mas se conserva, é "a síntese do tempo inteiro” (DELEUZE, 1988a, p. 144), e faz surgir a infância, a cada vez, inesgotável. Por essa temporalidade que lhe é própria, a cena infantil não é uma imagem-lembrança que prolonga um conjunto empírico, ela é o diferenciador a realçar novos traços de uma cena rarefeita, que entra, constantemente, em relação com elementos virtuais de um passado puro, que persiste no cone invertido bergsoniano. A cena infantil não funciona como uma memória de arquivos passados, trazidos ao presente; ela não é decalque, nem matériaforma de arquivo, é material-forças de experimentação, de fabulação, ela suscita devires e afirma a fluidez contínua de um tempo que dura, indivisível e elástico: simultaneidade, contemporaneidade e coexistência, em vez de sucessão, consecutividade e irreversibilidade (lógica de uma memória cronológica). Pode-se dizer, junto com Bergson (1964, p. 53), que "o organismo vivo é algo que dura", desde que "o seu passado se prolonga inteiro no seu presente, e aí permanece atual e agindo" (BERGSON, 1964, p. 53).

As imagens-lembrança, as lembranças de infância e as referências às histórias de família estão sobre um outro plano, o do tempo cronológico, pois, nesses casos, o real subentendido é confirmado por sua continuidade sucessiva, as relações temporais são prolongáveis, localizáveis, e passam por encadeamentos atuais irreversíveis. Referem-se, portanto, a um tempo cronológico, no qual não há lugar para rupturas em proveito de outras relações, potências ou intensidades. A cena infantil, por sua vez, duplica a história e está sempre a captar algum fragmento do passado puro, a dar-lhe visibilidade sem conduzilo ao presente que ele foi, e sem submetê-lo ao presente imediato para o qual ele é passado. "É como se alguns caminhos virtuais se colassem ao caminho real, que assim recebe deles novos traçados, novas trajetórias” (DELEUZE, 1997, p. 79). A imagem-cristal, sob a potência da função fabuladora, avança e puxa imagem virtual e imagem atual simultaneamente, e já não se diz inassinalável, mas, sim, indiscernível, “coloca no presente diferenças inexplicáveis; no passado, alternativas indecidíveis entre o verdadeiro e o falso" (DELEUZE, 1990, p. 161), e contribui para a invenção de uma infância que falta, uma infância-mundo, onde a força pura do tempo é ativada, e não a matéria empírica que se imprime no tempo.

Por isso, a infância é um acontecimento extracronológico, agita forças e intensidades, não formas dadas às formulações estáticas de essência e de ser, de estrutura ou de gênese, a infância não é qualidade ou propriedade de um corpo. No lugar do substantivo infância, que 
está subordinado ao verbo ser, podemos propor, aqui, o exercício do verbo infanciar, que indica devires e intensidades:

Se os infınitivos 'morrer', 'amar', 'mover', 'sorrir' etc., são acontecimentos, é porque há neles uma parte que sua realização não basta para realizar, um devir em si mesmo que está sempre, a um só tempo, nos esperando e nos precedendo como uma terceira pessoa do infinitivo, uma quarta pessoa do singular. (DELEUZE; PARNET, 1998, p. 78).

De acordo com Larrauri e Max (2000, p. 25), “não se pode falar assim, porém talvez se pode começar a pensar assim, a pensar em um mundo em que não há árvores e casas e adultos e crianças, [...] mas onde se 'arvoreia', se 'caseia', se 'adulteia', se "crianceia", porque interessa corromper os vestígios de um ser com contornos estáticos e impedir que árvores, casas, crianças, adultos sejam aprisionados no interior, inerte e rígido, do verbo ser. Ao liberar árvores, casas, adultos e crianças do estado de coisa e do significadosignificante, o que se têm são visibilidades, luminosidades:

É preciso rachar as coisas, quebrá-las. As visibilidades não são formas de objetos, nem mesmo formas que se revelariam ao contato com a luz e com a coisa, mas formas de luminosidade, criadas pela própria luz e que deixam as coisas e os objetos subsistirem apenas como relâmpagos, reverberações, cintilações. (DELEUZE, 1988b, p. 62).

Infanciar: estabelecer outras relações com a infância, agir, criar condições e modos para expandir e mapear as partículas infantis que se ramificam, se esparramam por todos lados e traçam cenas infantis outras, não costumeiras, que abrem os corpos a uma infância não cronológica, molecular. Infanciar: ampliar o que se vive e o que se diz da infância pode promover outras vidas infantis, traçar cenas na vida, no cotidiano, nas telas e nas ruas, que deem passagem a uma infância do mundo, da vida, de ninguém em particular, uma infância qualquer, de qualquer um, uma infância liberada dos contornos rígidos e engessadores do preestabelecido, antevisto, prescrito.

É exatamente assim que uma criança, um adulto e todo o resto podem se comunicar na invenção de uma infância por vir, em um exercício de fabulação, de abertura para o que não sabemos da infância e de questionamentos acerca do que cremos saber. Um devir-criança: um corpo que não imita ou quer se tornar uma criança, mas um corpo que, desprendido das suas unidades já conhecidas, experimenta as potências do infantil. Toda expansão de desejo expõe matérias não formadas, tensores, desafia mundos possíveis e mundos reais, produz bifurcações e lança os corpos em devires e experimentações, em uma gradação indiscriminada de intensidades, velocidades e lentidões.

Devir-criança é um movimento contemporâneo, criação cosmológica, invenção de mundo: um mundo que explode e a explosão de um mundo novo. Isso, afirma Deleuze, e mostra também o valor educacional da arte, por exemplo, quando povoa esses territórios:

A obra gaguejante de Biely, Kotik Letaiev, lançada num devir-criança que não é eu, mas cosmos, explosão de mundo: uma infância que não é a minha, que não é uma recordação, mas um bloco, um fragmento anônimo infinito, um devir sempre contemporâneo. (DELEUZE, 1997, p. 129). 
No caso da novela de Biely, citada por Deleuze, trata-se justamente da escrita das memórias primeiras da infância, sem conexão causal ou temporal entre elas, mas na coexistência sempre presente desse passado puro que é presente, contemporâneo. Mais perto de nós, as cenas infantis povoam a obra de poetas como o mato-grossense Manoel de Barros (2010) e fazem, da infância, uma memória inventada e, da memória, uma fabulação infantil. Dessa forma, a literatura, como forma de arte, ensina uma infância que não é pessoal, biográfica ou cronológica, mas mundana e presente: uma infância cósmica. “À sua maneira, a arte diz o que dizem as crianças. Ela é feita de trajetos e devires, por isso faz mapas, extensivos e intensivos” (DELEUZE, 1997, p. 78). Mas, já que entramos no mundo que a arte ensina, talvez seja hora de chamar um educador.

\section{Um educador político menino}

Para pensar a educação chamamos um educador e voltamos à América Latina. Retornamos a um registro aparentemente muito diferente, alguém inclusive associado a campos filosóficos enfrentados por Deleuze. Referimo-nos a Paulo Freire, o patrono da educação brasileira, título absurdamente questionado pelo atual governo brasileiro. Sim, precisamos ir à educação, porque se trata de educar as infâncias em uma relação atenta e sensivel às potências das vidas das pessoas, à expansão das potências, e não ao enfraquecimento ou à uniformização. Educar as infâncias ou, talvez melhor, infanciar a educação. Uma educação que afırme não o apequenamento ou apoucamento e infantilização dos estudantes, no sentido que propõe Piórkowski a Pimko, o diretor do colégio de Ferdydurke:

Se todos tivessem a sua habilidade de apequenar as pessoas, esta escola seria duas vezes maior! Bumbum, bumbum, bumbum! Creia-me, professor, que os adultos, infantilizados e apequenados por nós, são ainda melhores que as crianças em seu estado natural. (GOMBROWICZ, 2006, p. 59).

Contrário às proposições de Piórkowski e de Pimko, a tarefa da reniñez mundana, da cena infantil do mundo, exige considerar a educação da infância ou, melhor, uma educação infantil propriamente dita, uma infantilidade da educação que aprende com a infância e carrega a infância sempre, por toda vida, como o próprio Paulo Freire afirmou e recomendou, tantas vezes, nas cartas à Cristina (FREIRE, 2013), à Nathercinha (LACERDA, 2016) e em outras ocasiões.

A Cordilheira dos Andes está ficando linda. Tôda, branquinha, vestida de neve. Ontem de tarde eu fui com Elza, Madá e o marido dela "brincar" de fazer boneco de neve, num morro que fica perto de nossa casa. Depois de um dia muito frio e chuva, o morro ficou parecido com um Papai Noel, só que em lugar de algodão era neve. É muito bonito tudo isso. Às vezes eu me sinto como se fosse um menino também. Tenho vontade de correr. De brincar. De cantar. De dizer a todo mundo que gosto de viver. Você nunca deixe morrer em você a Natercinha de hoje. A menina que você é hoje deve acompanhar a mocinha que você vai ser amanhã e a mulher que será depois. (LACERDA, 2016, p. 55). 
Paulo Freire tem uma relação ambivalente e multiforme com a infância ${ }^{13}$. Por um lado, ele, que se preocupou pelas formas educacionais de pensar e enfrentar as mais diversas formas de opressão, não se ocupou da educação da infância, das crianças cronológicas. Por outro lado, desenvolveu uma relação íntima com a infância como uma espécie de condição para educar pessoas de qualquer idade. Paulo Freire ocupou-se da infância de muitos adultos, adultos infantes, expulsos do mundo letrado, sem a escrita, que não conheciam os códigos instruídos da linguagem. Paulo Freire também aprendeu a ler o mundo com todos esses que cruzaram seus caminhos. A sua simplicidade e abertura ao outro eram plenas, eram limpas, integras, sinceras. Seu interesse pela vida e pelos seres humanos levaram-no a muitos lugares, mas, sobretudo, levaram-no para esse espaço-tempo no qual todos os envolvidos em uma relação pedagógica aprendem a se sentir capazes de viver outra vida.

Paulo Freire recebeu da Biblioteca Comunale de Ponsacco, na província de Pisa, Itália, o título de Menino permanente (Bambino permanente), quando tinha 68 anos de idade, um 31 de março de 1990. É pelo menos chamativo alguém muito afastado da infância cronológica receber como prêmio um reconhecimento à sua permanência na infância. Esse prêmio permite perceber que uma infância não cronológica acompanhou sempre Paulo Freire, algo assim como se o mestre pernambucano estivesse instalado na infância, como se habitasse uma espécie de vida infantil ou reniñez permanente, para dizê-lo com o poeta chileno Gonzalo Rojas.

Essa relação com a infância, que com Rojas ganhava força poética criativa a-subjetiva e com Deleuze potência de criação filosófica conceitual, com Freire ganha impulso político para pensar e praticar uma educação atenta e sensível, a transformar os estados de coisas. Em outras palavras, o menino permanente é uma figura que inspira formas irruptivas e revolucionárias de exercer o poder de ensinar e aprender, não apenas com crianças, mas com pessoas de todas as idades. Nos parágrafos seguintes desdobraremos essas afirmações.

Antes, vale a pena perceber os sentidos biográficos dessa presença infantil, mesmo que eles não colmem ou acabem os sentidos da infância afirmados por Freire. Por um lado, a vivência educacional na infância cronológica ilumina e dá sentido ao pensamento educacional adulto: a maneira como Paulo Freire foi educado pelos seus pais, à sombra de uma mangueira, no quintal da casa da família, no bairro de Casa Amarela em Recife, inspira suas ideias para pensar a educação dos oprimidos de qualquer idade. As palavras do seu mundo de pássaros e árvores são as palavras que lhe permitem ler sua realidade e, a partir dela, o mundo. 0 ambiente é uma continuidade desse mundo e, sobretudo, o tempo se assemelha muito mais ao tempo do brincar infantil que ao da instrução numa instituição escolar. Paulo Freire alfabetiza-se em um tempo presente, de repetição quase infınita, sem limites para colocar suas perguntas, suas dúvidas, suas inquietações. Vive sua entrada ao mundo das letras num tempo infantil.

Por outro lado, Paulo Freire - e por isso foi reconhecido e premiado - mantém vivo esse sentimento, vivência ou experiência infantil até os últimos dias de sua vida: como Rojas e as crianças cronológicas, inventa palavras, sentidos outros para palavras já existentes ou recria palavras que caíram no abandono adulto; teima em questionar-se a

13- Para uma inspiração e ampliação do que segue, confira Infância (KOHAN, 2019). 
si mesmo e aos outros, lançando perguntas insólitas, inesperadas, insensatas, mostrandose curioso e inquieto com a vida individual e comum. E teima em sonhar e lutar pelos seus sonhos, em particular pelo sonho de uma educação emancipadora que dê lugar a um mundo mais justo para todos os seres humanos. Há uma infantilidade que persiste e abrange a obra e a vida de Paulo Freire por inteiro.

Dessa forma, Paulo Freire nasce, cresce e persiste na vida como um menino: meninomenino, jovem-menino, adulto-menino, velho-menino, engajado na construção de uma pedagogia também menina, infantil, da pergunta. Porque eis a questão e talvez as razões de tanto ódio (e medo?) levantado pelo pedagogo da esperança, do amor, da solidariedade: Paulo Freire pensava que o elemento mais importante que uma educação não pode deixar de ensinar é a pergunta (FREIRE; FAUNDEZ, 2017), ou seja, toda educação deveria ensinar a cuidar da infância, a nutri-la, a cuidá-la, a fazer dela não apenas uma etapa da vida, mas um modo de vida em todas as idades.

Por isso, a infância para Paulo Freire perpassa e muito o horizonte dos movimentos da cronologia. Paulo Freire quer, para educar meninos e meninas de todas as idades, educadores e educadoras meninas, infantis, de vida curiosa, inquieta, com gosto de perguntar e de querer crescer, criar, transformar e sem medo de sonhar (FREIRE; FAUNDEZ, 2017). A infância não é para Paulo Freire apenas algo que precise ser educado, mas a forma de uma vida verdadeiramente educadora, à medida que ela habita a curiosidade, inquietação, gosto de perguntar e criar que constituem a infância de todas as idades.

Assim, a meninice ou infância não é a atribuição de um tempo quantitativo, da (pouca) quantidade de tempo vivido, mas um atributo da qualidade de uma vida: "ninguém é velho só porque nasceu há muito tempo ou jovem porque nasceu há pouco" (FREIRE, 2013, p. 97). Por isso, em uma das cartas pedagógicas que compõem a Pedagogia da indignação, quando a infância cronológica passou-se faz muito tempo, com 75 anos, Paulo Freire pode dizer que, pela sua dinâmica para enfrentar os desafios e transformações da vida urbana, "é como se hoje fôssemos mais jovens do que ontem" (FREIRE, 2000, p. 31).

Desse modo, Paulo Freire aproxima-se surpreendentemente de Deleuze e Guattari, que afirmam que "saber envelhecer não é permanecer jovem, é extrair de sua idade as partículas, as velocidades e lentidões, os fluxos que constituem a juventude desta idade" (DELEUZE; GUATTARI, 1997, p. 70). A vida pode ser um caminho de rejuvenescimento: viver com juventude é extrair, da idade que se tem, do corpo que se é, os fluxos e as partículas que dão lugar a uma "involução criadora” (DELEUZE; GUATTARI, 1997, p. 73), às "núpcias anti-natureza” (DELEUZE; GUATTARI, 1997, p. 21), a uma força que não se espera, que irrompe, sem ser convidada ou antecipada.

Se ele está ligado à infância, não o está no sentido de uma regressão do adulto à criança, e da criança à Mãe, mas no sentido em que a criança, assim como o gêmeo dogon, que transporta consigo um pedaço de placenta, arranca da forma orgânica da mãe uma matéria intensa e desestratificada que constitui, ao contrário, sua ruptura perpétua com o passado, sua experiência, sua experimentação atuais. (DELEUZE; GUATTARI, 1996, p. 27). 
A velhice ou a juventude estão na qualidade de uma vida, na forma como questionamos e nos inquietamos com a vida em comum, na relação antinatural que estabelecemos com o mundo lá fora: a velhice está numa vida acomodada, não importa os anos que ela tenha; a juventude, a meninice, está em questionar, sonhar e lutar por um mundo de alegria, beleza e justiça para todos os seres humanos.

Mais ainda, Paulo Freire expande a força da meninice: ela deixa de ser uma possibilidade para se converter numa condição. Por isso, um educador ou educadora nunca pode deixar de ser menino ou menina, e uma vida educadora nunca pode deixar de ser uma vida menina ou infantil. Porque, se o deixasse, seria uma vida sem curiosidade, sem sonhos, sem luta, ou seja, uma vida não educativa. Assim, a vida de um educador ou educadora curiosa, incansável, insatisfeita, mobilizada, vivaz, esperançosa é infantil, sem importar a idade cronológica de quem a vive. Uma vida educadora infantil é uma vida que não se cansa de perguntar, sonhar e criar, que vive cada presente como se fosse a primeira vez que o vive, que está sempre começando a viver, e pensa que sempre é tempo para começar. Uma vida educadora infantil é uma vida de inquietação e mudança.

Paulo Freire é um desses exemplos em que o passar do tempo cronológico o aproxima ainda mais de uma infância que nunca abandona. Em uma palestra acerca de os Direitos Humanos, na Universidade de São Paulo (USP), em junho de 1988, com 66 anos, explicita belamente esse apego à infância:

Eu acho que uma das coisas melhores que eu tenho feito na minha vida, melhor do que os livros que eu escrevi, foi não deixar morrer o menino que eu não pude ser e o menino que eu fui, em mim. (FREIRE, 2001, p. 101).

Não deixar morrer o menino que não podemos ser. Paulo Freire também ajuda a pensar que a infância não é uma questão limitada à própria biografia; ao contrário, ela extrapola a particularidade de uma vida; ela diz respeito a todas as infâncias, a qualquer vida, a todas as vidas concebidas como uma com-unidade e, também, às possibilidades da infância e da vida serem de outra maneira do que elas são; manter viva a infância em nós, a que fomos e a que não pudemos ser, é uma forma de manter a nossa vida aberta à força transformadora e revolucionária da infância.

Não basta manter vivo o menino ou a menina que fomos: é preciso também manter, cuidar, dar vida a todos os meninos e meninas que não podemos, mas poderíamos ser. Precisamos manter viva uma infância sem idade, potência de vida, questionamento, curiosidade, surpresa, novidade: a infância que habita o mundo, como se fosse sempre uma primeira habitação, uma sensação de início, de abrir mundos.

Paulo Freire é muito sensível, na vida e na palavra, à essa infância mundana. Seu olhar, que nunca se ocupou da infância cronológica, é muito generoso e atento à infância sem idade. 0 grande educador pernambucano foi sempre muito sensível às condições de vida mundanas, em particular às vidas excluídas, oprimidas, esfarrapadas. Percebemos sua sensibilidade e, também, sua generosidade no seu desejo de se envolver com a humanidade inteira, na esperança de que a humanidade encontre condições de vida mais humanas para 
todos. Percebemos, também, nessa intervenção de Paulo Freire, uma postura do educador a respeito da relação entre educação e infância: a infância que, usualmente, é algo que os educadores colocam fora de nós como o que precisa ser educado, encontra-se, nessa afırmação de Paulo Freire, como algo que não apenas nos ajuda a educar meninos e meninas, mas, também, nos educa a nós mesmos, adultos cronológicos, dentro e fora das salas de aula. E, sobretudo: ela é uma condição para que uma vida educadora seja digna de ser vivida como tal.

\section{Palavras finais}

Um conceito tem atravessado o presente ensaio: o tempo. Na poesia de Gonzalo Rojas poderia ver-se um intento de voltar atrás no tempo, de romantizar a infância ou querer retornar a um passado nostálgico e idealizado. Mas, na verdade, o esforço do poeta é por honrar o tempo presente da infância que é, também, o tempo da escrita poética. Eis o tempo da reniñez: um tempo que não passa, durativo, atento e sensível à palavra do mundo.

Gilles Deleuze introduz a cena infantil para pensar a infância: sinaliza a interrupção do tempo cronológico e a afırmação de um tempo aion, um vetor que atravessa todas as idades da linha cronológica. Pensar a infância a partir da cena infantil é restaurar à infância um tempo propriamente infantil, como diz Heráclito no seu icónico fragmento $52 .{ }^{14}$ Aión, o tempo da infância, é, também, o tempo da arte e da filosofia. E é, igualmente, atentar para o poder revolucionário do menor, molecular, mínimo, ínfimo.

Por fim, Paulo Freire expande o tempo da infância para todas as idades: invasão aiónica de khrónos, que torna urgente aos educadores e às educadoras de todas as idades habitar um tempo infantil, um presente curioso, que olha o mundo com estranheza e pergunta, inquieto, por que o mundo é como é e de que outras maneiras ele poderia ser. É preciso habitar esse tempo de infância, justamente em terras da educação, para revolucionar a própria educação política, deslocando seu foco da educação do outro para a educação de si; da formação da infância para a escuta e atenção à força revolucionário da infância e do modo infantil de habitar o mundo. Escutar, atentar e, em última instância, viver a infância é uma condição de um educador político, porque o tempo da infância é também o tempo de uma educação transformadora dos modos de vida instituídos.

Em um texto dedicado a pensar a potencialidade do mínimo, do ínfimo, da minúcia, como forças que podem nos deslocar dos lugares comuns que habitamos no pensamento, quando pensamos a infância, Carlos Skliar afırma que o modo dominante de relação com a infância, incluso (ou sobretudo) nas instituições escolares é o de interrupção da infância (SKLIAR, 2018). De todas as formas que essa interrupção toma, resulta-nos particularmente significativa a interrupção do tempo da infância:

0 tempo da infância morre, pois começa a fazer parte da fileira dos eventos ordenados, utilitários, aproveitáveis; das horas da ficção à perda da invenção, do tempo que parece esfumaçar-se, ao tédio. [...] A dor de infância acontece no momento em que interrompe a intensidade do instante

14- Aion pais paizo: "0 tempo é uma criança que brinca" (DK 22 B 52; cf. COSTA, 2002). Para uma discussão mais alargada das temporalidades gregas, confira KOHAN (2004). 
e se força à tirania da sequência: ali o tempo se torna demasiadamente extenso, está estendido até o tédio, a insignificância, até outra duração, a da cronologia simples e pura. Tudo o que era simultâneo, disjuntivo, caótico se torna sucessão, princípio e finalidade e, nessa interrupção da solidão e da ficção, varre-se a invenção, a intuição da liberdade, a suposição do ilimitado, a crença na totalidade e, por isso, também, já não há salto no escuro, já não há ensaio nem experiência. (SKLIAR, 2018, p. 253).

“[...] Tudo o que era simultâneo, disjuntivo, caótico se torna sucessão, princípio e finalidade [...]”, afirma Carlos Skliar (2018, p. 53). Tudo o que é reniñez, cena de infância, menino permanente torna-se uma infância das idades, etapa da vida, fase formativa e assim perde a sua força, intensidade, duração disruptiva da sequência produtiva ancorada na lógica cronológica. A instituição interrompe a infância, inclusive em projetos feitos em nome de palavras nobres como democracia, cidadania ou ética.

Consideremos um exemplo. Em fevereiro de 2017, no meio de uma conversa com crianças de uma escola pública em Bari, Itália, elas perguntavam sobre quem tinha inventado a Filosofia (KOHAN, 2018). Devolvemos a pergunta e muitas hipóteses começaram a ser levantadas. Uma das crianças disse: "A filosofia foi inventada por uma pessoa que queria lembrar que tinha sido uma criança”. Eis o sentido principal de nossa escrita, na fala infantil de uma criança. Talvez seja mera coincidência que se trate de uma criança cronológica. Não estamos seguros. Em qualquer caso, vale a pena deter-se a pensar nessa afırmação infantil.

Há muitos projetos bem-intencionados para levar a filosofia até as crianças ${ }^{15}$. Esses projetos, geralmente, são colocados como educadores da infância, na formação de cidadãos democráticos, críticos e outras palavras de ordem. ${ }^{16}$ No presente texto, temos sugerido uma possibilidade diferente, quase inversa. A palavra infantil o diz: o sentido da presença da filosofia na escola, ou de modo mais geral de uma educação filosófica, não é fazer da infância algo diferente do que ela é, mas nos lembrar e nos levar à (um tempo de) infância, ou para dizê-lo com nossos interlocutores infantilmente adultos: a viver, a qualquer idade, uma reniñez, uma cena infantil, um permanecer na infância como presente. Há um valor político nessas formas de expressão de uma temporalidade infantil que talvez seja o caso de atentar e cuidar muito mais do que interromper.

\section{Referências}

BARROS, Manoel de. Memórias inventadas: a infância. São Paulo: Planeta, 2010.

BERGSON, Henri. A evolução criadora. Rio de Janeiro: Delta, 1964.

BERGSON, Henri. Matéria e memória: ensaio sobre a relação do corpo com o espírito. Paulo: Martins Fontes, 1999.

15- Confira, por exemplo, Childhood \& philosophy (2019).

16- Recentemente, Santi (2019) apresenta um modo, colaborativo, de pensar essa formação cidadã. 
CHILDHOOD \& PHILOSOPHY, Rio de Janeiro, v. 15, 2019. Dossier Investigação filosófica com crianças: novas vozes. Disponível em: http://filoeduc.org/nefiedicoes/colecoes.php. Acesso em: 18 ago. 2020.

CNCA. Consejo Nacional de la Cultura y las Artes; GONZÁLEZ FULLE, Beatriz; CLARO EYZAGUIRRE, Alejandra. Alumbrado por el relámpago: Gonzalo Rojas y su poesía. Santiago de Chile: Consejo Nacional de la Cultura y las Artes, 2017. (Cuaderno pedagógico).

COSTA, Alexandre. Heráclito: fragmentos contextualizados. Rio de Janeiro: Difel, 2002.

DELEUZE, Gilles. Cinema 2: a imagem-tempo. São Paulo: Brasiliense, 1990.

DELEUZE, Gilles. Crítica e clínica. São Paulo: 34, 1997.

DELEUZE, Gilles. Diferença e repetição. Rio de Janeiro: Graal, 1988a.

DELEUZE, Gilles. Foucault. São Paulo: Brasiliense, 1988b.

DELEUZE, Gilles. Mil platôs: capitalismo e esquizofrenia. v. 4. São Paulo: 34, 1997.

DELEUZE, Gilles; GUATTARI, Félix. Mil platôs: capitalismo e esquizofrenia. v. 3. Rio de Janeiro: 34, 1996.

DELEUZE, Gilles; PARNET, Claire. Diálogos. São Paulo: Escuta, 1998.

FREIRE, Paulo. À sombra desta mangueira. Organização e notas de Ana Maria Araújo Freire. Rio de Janeiro: Paz e Terra, 2013.

FREIRE, Paulo. Cartas a Cristina: reflexões sobre minha vida e minha práxis. São Paulo: Paz e Terra, 2015.

FREIRE, Paulo. Pedagogia da indignação. Cartas pedagógicas e outros escritos. São Paulo: Unesp, 2000.

FREIRE, Paulo. Pedagogia dos sonhos possíveis. São Paulo: Unesp, 2001.

FREIRE, Paulo; FAUNDEZ, Antonio. Por uma pedagogia da pergunta. Rio de Janeiro: Paz e Terra, 2017.

GOMBROWICZ, Witold. Ferdydurke. São Paulo: Companhia das Letras, 2006.

KOHAN, Walter Omar. A conversation with children about chidren... Journal of Philosophy in Schools, Birmingham, v. 5, n. 2, p. 95-126, 2018.

KOHAN, Walter Omar. A infância da educação: o conceito devir-criança. In: KOHAN, Walter Omar (org.). Lugares da Infância: filosofia. Rio de Janeiro: DP\&A, 2004. p. 51-68.

KOHAN, Walter Omar. Paulo Freire mais do que nunca: uma biografia filosófica. Belo Horizonte: Vestígio, 2019.

L'ABÉCÉDAIRE de Gilles Deleuze. Entrevista com Gilles Deleuze. Editação: Brasil, Ministério de Educação, "TV Escola", 2001. Paris: Éditions Montparnasse, 1997. 1 videocassete, VHS, cor. 
LACERDA, Nathercia. A casa e o mundo lá fora: cartas de Paulo Freire para Nathercinha. Rio de Janeiro: Zit, 2016.

LARRAURI, Maite; LARRAURI, Max. El deseo según Gilles Deleuze. Valencia: Tàndem, 2000.

MASSCHELEIN, Jan. Em defesa da escola. Belo Horizonte: Autêntica, 2014.

ROJAS, Gonzalo. Concierto: antología poética (1935-2003). Barcelona: Vegap, 2004.

R0JAS, Nelson. Exilio y transtierro en dos poemas de Gonzalo Rojas. Estudios Filológicos, Valdívia, v. 56, p. 119-131, 2015.

SANTI, Marina. Collaborative problem-solving and citizenship education: a philosophical escape in the age of competencies. Childhood \& Philosophy, Rio de Janeiro, v. 15, p. 1-19, 2019.

SKLIAR, Carlos. Infâncias da linguagem, infâncias da infância, memórias de infâncias: depois é tarde demais. Childhood \& Philosophy, Rio de Janeiro, v. 14, n. 30, p. 245-260, 2018.

Recebido em: 07.04.2020

Revisado em: 01.07.2020

Aprovado em: 04.08.2020

Walter Omar Kohan é professor titular do Departamento de Estudos da Infância (DEDI) e do Programa de Pós-graduação (PROPEd) da Universidade Estadual do Rio de Janeiro (UERJ). Pesquisador do CNPq e da FAPERJ. Coordena o Projeto "Filosofia na infância da vida escolar" (CAPES-PrInt). Coordena o projeto "Em Caxias a Filosofia em-caixa?" e é coeditor do periódico Childhood \& Philosophy.

Rosana Aparecida Fernandes é professora adjunto A de Filosofia da educação, na Universidade Federal do Rio Grande do Sul (UFRGS), no Departamento de Estudos Básicos (DEBAS). Pesquisa, especialmente, as seguintes temáticas: Ensino de Filosofia, Filosofia para/ com Crianças, Filosofia da Educação, Currículo, Filosofias da Diferença, Cinema, Infância. 